\title{
SHORT TERM OPERATION PLANNING OF HYDRO STATIONS CONSIDERED AS PRICE MAKERS USING THE MATLAB LINPROG ${ }^{\oplus}$ FUNCTION
}

\author{
Manuel Castro ${ }^{1}$, João Tomé Saraiva ${ }^{1,2, *}$, José Carlos Sousa ${ }^{3}$ \\ ${ }^{1}$ Faculdade de Engenharia da Universidade do Porto, Rua Dr. Roberto Frias, 4200465 Porto, Portugal \\ ${ }^{2}$ INESC TEC, Rua Dr. Roberto Frias, 4200465 Porto, Portugal \\ ${ }^{3}$ EDP Gestão da Produção, Rua Ofélia Diogo da Costa, 115, 4149022 Porto, Portugal \\ *jsaraiva@fe.up.pt
}

Keywords: Hydro stations, Short term planning, HSP problem, price makers, electricity markets

\begin{abstract}
The restructuring of power systems induced new challenges to generation companies in terms of adequately planning the operation of power stations in order to maximize their profits. In this scope, hydro resources are becoming extremely valuable given the revenues that their operation can generate. In this paper we describe the application of the Matlab ${ }^{\circledR}$ Linprog optimization function to solve the Short Term Hydro Scheduling Problem, HSP, admitting that some stations are installed in the same cascade and that some of them have pumping capabilities. The optimization module to solve the HSP problem is then integrated in an iterative process to take into account the impact that the operation decisions regarding the hydro stations under analysis have on the market prices. The updated market prices are then used to run again the HSP problem thus enabling considering the hydro stations as price makers. The developed approach is illustrated using a system based on the Portuguese Douro River cascade that includes 9 hydro stations (4 of them are pumping stations) and a total installed capacity of $1485 \mathrm{MW}$.
\end{abstract}

\section{Introduction}

The main objective of this work was the development of an application to solve the short term Hydro Scheduling Problem, HSP, considering that the hydro stations are price makers, that is, taking into account the impact of their operation decisions on the market prices. Hydro stations are an important source of clean electricity in several countries and so in recent years generation companies started to direct their attention once again to hydro resources. Portugal currently has about $5600 \mathrm{MW}$ of its generation capacity installed in hydro stations (about $30 \%$ of the total) and it is estimated that about $40 \%$ of its hydro resources are still unused. As a result of this renewed interest, in 2010 several auctions to concession new hydro generation were launched by the government so that this capacity is expected to increase to about $7000 \mathrm{MW}$ (about 37\% of the total) till 2020 . This justifies the interest of generation companies to optimize the operation of these stations, namely in view of their participation in the Iberian Electricity Market and also given that several stations are installed in the same river or water basin and that an increasing number are pumping stations.

In order to understand this renewed interest for the HSP problem it should also be mentioned that the electricity sector evolved from a vertical structure in which a single company, at least in each geographical area, included all the activities of the value chain, to a decoupled and decentralized industry in which competition was promoted at the generation and at the retailing activities. On the other hand, network transmission and distribution activities are typically provided in terms of regulated concessions and the relationship between generation and demand is done via centralized pool markets or by bilateral contracts. The Iberian Electricity Market, MIBEL, was launched in 2007 as an extension of the Spanish market that already existed since 1998. It has a mixed model organization including a symmetric day ahead market based on 24 trading hourly periods and admitting complex bids. It also includes a platform to trade standardized bilateral contracts and a number of intraday markets for shorter term adjustments. The presence of bids from hydro stations is very important in the market because in rainy periods low or zero price bids strongly contribute to decrease the market price.

Given the relevance of hydro generation in Portugal and its expected increase in the near future, it is important to develop tools to optimize the operation of these stations namely if they are installed in the same river and if some of them are pumping hydro stations. On the other hand, since hydro capacity cannot be neglected in the global generation mix, it would be unrealistic to model the HSP problem considering hydro stations just as price takers. In fact the generation and pumping decisions regarding about 37\% of the installed capacity in Portugal will impact on the market prices, so that these stations should rather be modelled as price makers.

Having in mind these ideas, this paper is structured as follows. After this Introduction, Section 2 presents a short overview on the HSP problem and Section 3 details its mathematical formulation, admiting that electricity prices along the planning horizon are input to the problem, that is, hydro stations are prices takers. 
Then, Section 4 details the iterative process to take into account the impact of the HSP operation decisions in the prices, thus defining an iterative process. Section 5 presents the results that were obtained applying this approach to a system based on the hydro cascade of the Portuguese section of the Douro River and finally Section 6 enumerates the most relevant conclusions.

\section{Overview of the Hydro Scheduling Problem}

The restructuring of power system and the introduction of market mechanisms for instance under the form of day ahead markets induced generation companies to adequately plan the operation of their assets in order to maximize their profits. In countries having a large share of hydro resources, this concern contributed to the renewed interest on the HSP problem to identify the most adequate operation strategy in view of the available water resources. The HSP is a non-linear problem that should include temporal and spatial interdependencies between stations. Admitting we are planning the operation of station $\mathrm{i}$ in period $\mathrm{k}$ and assuming an ideal hydro circuit, the generated power is given by (1) in which the gravity acceleration is $9,8 \mathrm{~ms}^{-2}$, the density of the water is $1000 \mathrm{~kg} / \mathrm{m}^{3}, \mathrm{q}_{\mathrm{ik}}$ is the water flow in $\mathrm{m}^{3} \mathrm{~s}^{-1}$, $\mathrm{h}_{\mathrm{ik}}$ is the water head in $\mathrm{m}$ and $\mu_{\mathrm{T}}$ is the generation efficiency factor.

$$
\mathrm{P}_{\text {Tik }}=9,8.1000 \cdot \mathrm{q}_{\mathrm{ik}} \cdot \mathrm{h}_{\mathrm{ik}} \cdot \mu_{\mathrm{T}}
$$

The power has a non-linear behaviour regarding the water flow due to the losses in the water circuit and this effect is usually considered modifying (1) in order to include the head loss term. In expression (2) $\beta$ represents the head loss coefficient and for each particular value of $\mathrm{h}_{\mathrm{ik}}$ it is obtained a non-linear expression relating $\mathrm{q}_{\mathrm{ik}}$ and $\mathrm{P}_{\mathrm{Tik}}$ thus leading to a family of curves. In this sense, Figure 1 displays one of these curves for a particular value of the head (blue curve).

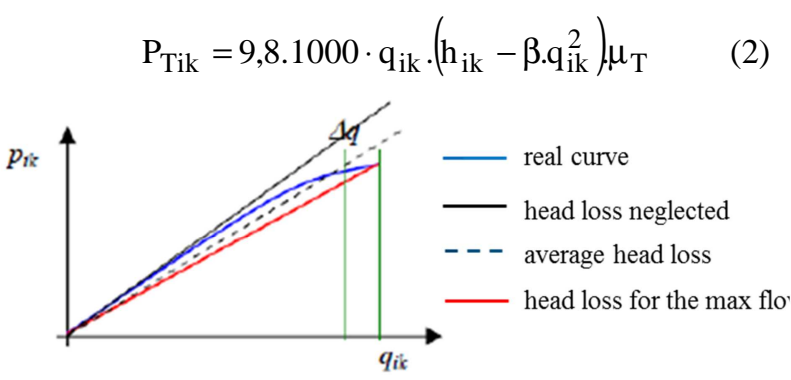

Fig.. 1. Generated power in terms of the flow and possible approximations.

The head loss coefficient $\beta$ is calculated using (3) where $\Delta \mathrm{hn}$ is the nominal head loss and qn is the nominal discharge flow. After obtaining $\beta$, the generated power $\mathrm{P}_{\text {Tik }}$ and the water flow, $\mathrm{q}_{\mathrm{ik}}$, have a non-linear relation due to the term $\beta . q_{i k}^{2}$ as it is illustrated by the blue curve in Figure 1.

$$
\beta=\frac{\Delta \mathrm{hn}}{\mathrm{qn}^{2}}
$$

The non-linear dependency between the power, the head and the water flow justified the adoption of several approximations illustrated in Figure 1 to simplify the problem compromising as little as possible the accuracy and realism of the models. One possible approximation corresponds to neglect the head loss term in (2). This means that for each particular value of $h_{i k}$ a linear approximation would be used. This approximation would be located above the real curve since the head loss term was not considered. As a consequence, for large flows the quality of the approximation was poorer. This is a most undesirable feature because the experience shows that, when generating, hydro stations are operating for large values of the flows in order to increase their output power and revenues.

A second possibility corresponds not only to neglect the head loss term but also to consider a fixed value for the head, $h_{i k}$. This is useful for stations with large reservoirs so that the head is very little changed after some hours of operation. However, it proves to be unrealistic for run of river stations or small reservoirs in which the capacity and the head can easily get reduced after some hours of operation. The maximum discharge flow can also be used to obtain a constant value for the head loss. In this case the approximated curve is located below the real one and so the error is smaller for large values of the flow. This is interesting since when operating it is usual that hydro stations generate at full capacity.

To maximize the profits and turn the operation more flexible, the installation of reversible groups is becoming increasingly interesting, either when building new stations or by substituting equipments in existing stations. In case of pumping, the power consumed by station $\mathrm{i}$ in period $\mathrm{k}$ is given by (4) where $\mu_{\mathrm{P}}$ is the pumping efficiency factor.

$$
P_{P i k}=9,8.1000 \cdot q_{i k} \cdot\left(h_{i k}+\beta \cdot q_{i k}^{2}\right) / \mu_{P}
$$

The described non-linear nature of the hydro scheduling problem justified the use of several non-linear optimization techniques as the ones in $[1,2,3]$. Along time, the use of dynamic programming has also been reported as in $[4,5]$ but the curse of dimensionality affecting dynamic programming always turned difficult the analysis of realistic hydro systems over meaningful horizons. In an attempt to simplify the problem, several approximations have been tested eventually leading to linear formulations as the ones in $[2,6]$ usually using a linear relation between the power and the flow. Other models include binary variables as [7] to represent the state of each station in each period leading to mixed integer linear or non-linear formulations. More recently, metaheuristic techniques started to be applied to this problem including Neural Networks [8], Simulated Annealing [9], Tabu Search [10], Genetic Algorithms $[11,12]$ and particle swarm approaches [13]. Finally, several publications as $[1,14]$ use an iterative procedure 
in which the head is updated using the value obtained for $q_{i k}$ in the previous iteration and the $\beta$ coefficient is calculated using expression (3).

\section{Formulation of the HSP Problem}

In this section we detail the mathematical formulation of the Short-Term Hydro Scheduling Problem, HSP, assuming that a set of prices are input to the problem and that these prices remain unchanged. Then, Section 4 discusses the integration of this model in a more global algorithm in which hydro stations will be considered as price makers.

The Short-Term HSP problem aims at maximizing the profit of a set of hydro power plants over a horizon typically of one day or one week with an hourly discretization and it is formulated by (5) to (13). This implicitly means there is an upper level model run for a medium/long term horizon that provides the initial and final volumes of each station to be used in the short term HSP problem.

$$
\begin{array}{ll}
\max \sum_{\mathrm{i}=1 \mathrm{k}=1}^{\mathrm{I}} \sum_{\mathrm{k}}^{\mathrm{K}}\left[\left(\pi_{\mathrm{k}} \cdot \mathrm{P}_{\mathrm{Tik}}\right)-\left(\pi_{\mathrm{k}} \cdot \mathrm{P}_{\mathrm{Pik}}\right)-\left(\mathrm{ps} \cdot \mathrm{s}_{\mathrm{ik}}\right)\right] \\
\text { subj. } \quad \mathrm{v}_{\mathrm{ik}}=\mathrm{v}_{\mathrm{i}(\mathrm{k}-1)}+\mathrm{a}_{\mathrm{ik}}-\mathrm{q}_{\mathrm{Tik}}-\mathrm{s}_{\mathrm{ik}}+\mathrm{q}_{\mathrm{Pik}}+ \\
\quad+\sum_{\mathrm{m} \in \mathrm{Mi}}\left(\mathrm{q}_{\mathrm{Tm}\left(\mathrm{k}-\phi_{\mathrm{m}}\right)}+\mathrm{s}_{\mathrm{m}\left(\mathrm{k}-\lambda_{\mathrm{m}}\right)}-\mathrm{q}_{\mathrm{Pm}\left(\mathrm{k}-\omega_{\mathrm{m}}\right)}\right) \\
\mathrm{vol}_{\mathrm{i}}^{1 \mathrm{~min}} \leq \mathrm{q}_{\mathrm{Tik}}+\mathrm{s}_{\mathrm{ik}}-\mathrm{q}_{\mathrm{Pik}} \leq \mathrm{vol}_{\mathrm{i}}^{1 \mathrm{max}} \\
\mathrm{v}_{\mathrm{i}}^{\min } \leq \mathrm{v}_{\mathrm{ik}} \leq \mathrm{v}_{\mathrm{i}}^{\max } \\
\mathrm{qT}_{\mathrm{i}}^{\min } \leq \mathrm{qT}_{\mathrm{ik}} \leq \mathrm{qT}_{\mathrm{i}}^{\max } \\
\mathrm{qP}_{\mathrm{i}}^{\min } \leq \mathrm{qP}_{\mathrm{ik}} \leq \mathrm{qP}_{\mathrm{i}}^{\max } \\
0 \leq \mathrm{s}_{\mathrm{ik}} \leq \infty \\
\mathrm{v}_{\mathrm{iK}}=\mathrm{vol}_{\mathrm{iK}} \\
\mathrm{i}=1, \ldots, \mathrm{I} ; \mathrm{k}=1, \ldots, \mathrm{K} ; \mathrm{m}=1, \ldots, \mathrm{L}
\end{array}
$$

In this formulation:

- I, i - number of reservoirs and index for a reservoir;

- K , k - number of scheduling hourly periods and index for a particular hour;

- Mi - set of upstream reservoirs directly connected with reservoir i;

- $\mathrm{m}$ - index for a reservoir in set $\mathrm{Mi}$;

- $\pi_{\mathrm{k}}$ - electricity market price in hour $\mathrm{k}$;

- $\mathrm{P}_{\mathrm{T}_{\mathrm{ik}}}$ - generated power in station $\mathrm{i}$, hour $\mathrm{k}$;

- $\mathrm{P}_{\mathrm{P}_{\mathrm{ik}}}$ - pumping power in reservoir $\mathrm{i}$, hour $\mathrm{k}$;

- ps - penalty factor for spills;

- $s_{\mathrm{ik}}-$ spill of reservoir $\mathrm{i}$, in hour $\mathrm{k}$;

- $\mathrm{v}_{\mathrm{ik}}$ - volume of reservoir $\mathrm{i}$, in hour $\mathrm{k}$;

- $a_{i k}-$ inflow of reservoir $i$, in hour k;

- $\mathrm{q}_{\text {Tik }}$ - discharge volume of reservoir i, in hour $\mathrm{k}$;

- $\mathrm{q}_{\mathrm{Pik}}$ - pumping volume of reservoir $\mathrm{i}$, in hour $\mathrm{k}$;
- $\phi_{\mathrm{m}}, \lambda_{\mathrm{m}}, \omega_{\mathrm{m}}-$ delays of turbine discharge, spill and pumping volumes;

- $\operatorname{vol}_{\mathrm{i}}^{1 \mathrm{~min}}, \mathrm{vol}_{\mathrm{i}}^{1 \mathrm{max}}$ - minimum and maximum volumes of reservoir $\mathrm{i}$ considering for instance ecologic needs;

- $v_{i}^{\min }, v_{i}^{\max }-$ level volume limits of reservoir $i$;

- $\mathrm{qT}_{\mathrm{i}}^{\min }, \mathrm{qT}_{\mathrm{i}}^{\max }$ - turbine discharge limits for station i;

- $\mathrm{qP}_{\mathrm{i}}^{\min }, \mathrm{qP}_{\mathrm{i}}^{\max }$ - pumping volume limits for station i;

- vol $_{\mathrm{iK}}$ - volume of reservoir $\mathrm{i}$ set for the last period, $\mathrm{K}$.

The objective function (5) maximizes the profit of the operation of the I hydro stations under analysis given that at each period $\mathrm{k}$ the generated power output of station $\mathrm{i}, \mathrm{P}_{\mathrm{T}_{\mathrm{ik}}}$, is sold at the market price $\pi_{\mathrm{k}}$. If station $\mathrm{i}$ is pumping water then electricity is bought at price $\pi_{\mathrm{k}}$ thus corresponding to a cost. If spilling occurs then the third term in (5) penalizes these situations. The generated or pumping powers used to compute the profit are obtained using (2) or (4) admitting that the nominal value of the head is used and that in each case the head loss is fixed and calculated using the maximum flow. This means that the power will become linear regarding the discharge or the pumping flow as discussed in Section 2.

The set of constraints includes equality constraints (6) one per station $\mathrm{i}$ and per period $\mathrm{k}$. Each of them relates the volume $v_{i k}$ with the volume of reservoir $i$ in period $\mathrm{k}-1$, with the inflow, with the outflow volume, with the water spill and with the water balance in the reservoirs upstream reservoir $i$ and directly connected with it. The upstream volumes to be considered depend on the design of the hydro system, namely on the time that water takes to arrive from an upstream station to a downstream one. Constraints (7) establish minimum and maximum limits for the liquid output volume of reservoir i, modelling for instance minimum flow requirements related with agriculture uses or ecological reasons. Constraints (8) bound the hourly volumes of reservoir $\mathrm{i}$ and (9) and (10) limit the generation and pumping flows of station $i$ in period $k$. Finally, constraints (11) indicate that the water spill is nonnegative and (12) sets the volume of reservoir $i$ at the end of the planning period, that is, at the end of hour $\mathrm{K}$.

\section{Hydro Stations as Price Makers}

In order to consider the impact of the operation decisions on the market prices, it was designed an iterative process that requires inputting a set of initial electricity prices as well as estimates for the aggregated buying and selling market curves of the remaining market agents. Then, the linearized HSP problem detailed in Section 3 is solved using the set of initial hourly market prices and using the Linprog function of 
$M a t l a b \AA$. The results are then used to update the hourly aggregated selling and buying curves associated with the bids of all other market agents as illustrated in Figures 2 and 3.

If a station $\mathrm{i}$ is generating at hour $\mathrm{k}$ (Figure 2), then the selling curve is shifted to the right including a new segment at zero price from A to B. If no pumping exists in that hour, then the new price gets reduced from P1 to $\mathrm{P} 2$, admitting that the buying curve is unchanged. Conversely, if station $\mathrm{i}$ is pumping in hour $\mathrm{k}$ (Figure 3) than a new buying segment at the maximum price is included in the aggregated buying curve from $\mathrm{E}$ to $\mathrm{F}$ thus originating the increase of the price from P3 to P4, admitting that the selling curve remains unchanged. Of course, in real systems at hour $\mathrm{k}$ some stations are generating and some other can be pumping which means that at the same hour both the selling and the buying curves are shifted to the right depending on the generation and pumping powers. At the end of this process and for every hour k, we get a new set of prices that are used to run again the HSP problem in order to refine the operation decisions. This iterative process ends when in two consecutive iterations the operation decisions for all stations remain unchanged.

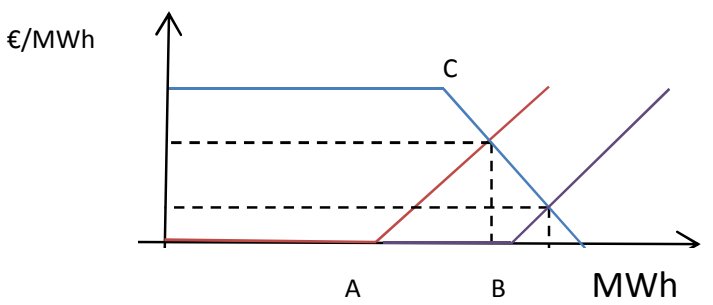

Fig. 2. Linearization of the market curves - generation decision.

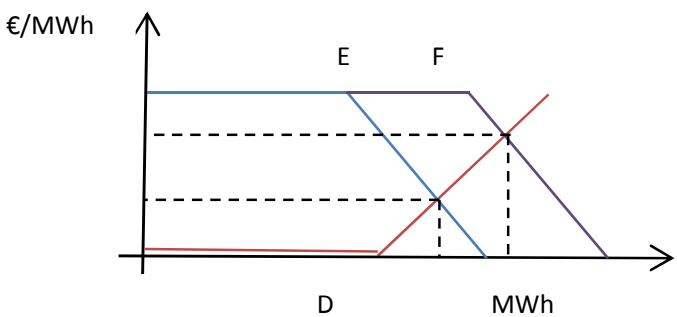

Fig. 3. Linearization of the market curves - pumping decision.

\section{Case Study}

The iterative approach outlined above was tested using the cascade of 9 hydro stations of the Portuguese section of the Douro River (see Figure 4). The total installed capacity is $1485 \mathrm{MW}$ and stations B, C, E and $\mathrm{H}$ are pumped hydro. Their main characteristics are provided in Tables 1 and 2.

The tests were conducted for a period of 168 hours and different initial and final volumes in the reservoirs were used to model dry and humid operation conditions. For illustration purposes, we will now present the results that were obtained for typical wet and dry weeks. The HSP problem run in every iteration of the algorithm has
8913 constraints and 3696 decision variables (given the period of 168 hours and 5 stations without pumping and 4 with pumping).

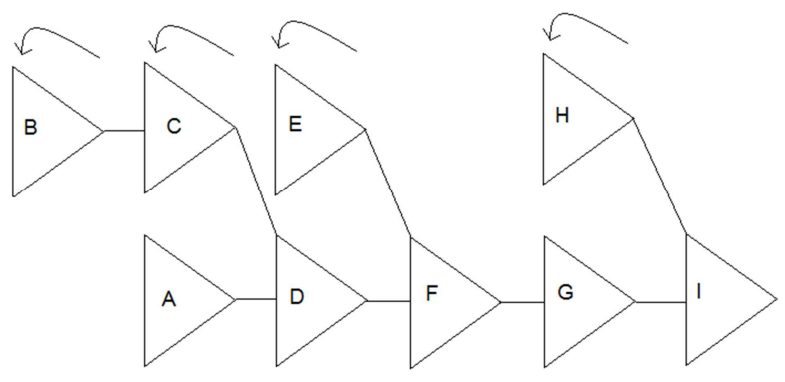

Fig. 4. Scheme of the Portuguese Douro river cascade.

Table 1 Main characteristics of the hydro stations (without pumping)

\begin{tabular}{|l|l|l|l|l|l|}
\hline Stations & A & D & F & G & I \\
\hline Max. Volume $\left(\mathrm{hm}^{3}\right)$ & 83 & 97 & 95 & 148 & 110 \\
\hline Min. Volume $\left(\mathrm{hm}^{3}\right)$ & 71 & 85 & 82 & 132 & 94 \\
\hline Generation efficiency (\%) & 0,90 & 0,92 & 0,93 & 0,91 & 0,86 \\
\hline Generation flow $\left(\mathrm{m}^{3} / \mathrm{s}\right)$ & 1077 & 900 & 744 & 705 & 1350 \\
\hline Generation power (MW) & 186 & 240 & 180 & 201 & 117 \\
\hline
\end{tabular}

Table 2 Main Characteristics of the hydro pumping stations

\begin{tabular}{|l|l|l|l|l|}
\hline Stations & B & C & E & H \\
\hline Max. Volume $\left(\mathrm{hm}^{3}\right)$ & 1095 & 31 & 100 & 106 \\
\hline Min.Volume $\left(\mathrm{hm}^{3}\right)$ & 917 & 18 & 88 & 84 \\
\hline Generation efficiency (\%) & 0,89 & 0,89 & 0,87 & 0,89 \\
\hline Generation flow (m $\left.{ }^{3} / \mathrm{s}\right)$ & 170 & 120 & 310 & 320 \\
\hline Generation power (MW) & 141 & 31 & 249 & 134 \\
\hline Pumping efficiency (\%) & 0,91 & 0,91 & 0,88 & 0,92 \\
\hline Pumping power (MW) & 141 & 31 & 181 & 148 \\
\hline Pumping flow (m 3 /s) & 135 & 85 & 165 & 279 \\
\hline
\end{tabular}

\subsection{Case 1-Wet Week}

In this case, we used inflows typical for a wet period provided by EDP Gestão da Produção, SA and the initial and final volumes were set at $20 \%$ of the maximum values. Figure 5 presents the initial market prices and the final ones at the end of the iterative process described in Section 4. Figure 6 represents the generation and pumping powers as well as the final electricity market prices. After the first run of the HSP problem the profit is $9.804 .668,60 €$ and this value is reduced by $8,4 \%$ to $8.981 .331,10 €$ once the iterative process converges after 5 iterations.

These results indicate that the large inflows enabled using the hydro stations very intensively as generators. Due to the large inflows and the low value set for the final volumes, pumping was only used in hour 149 (lowest electricity price along the week). This pumping operation was required to enforce the final volume 
constraints. As a result, the profit has a very large value and as generation is always larger than pumping, the final market prices are below the initial ones.

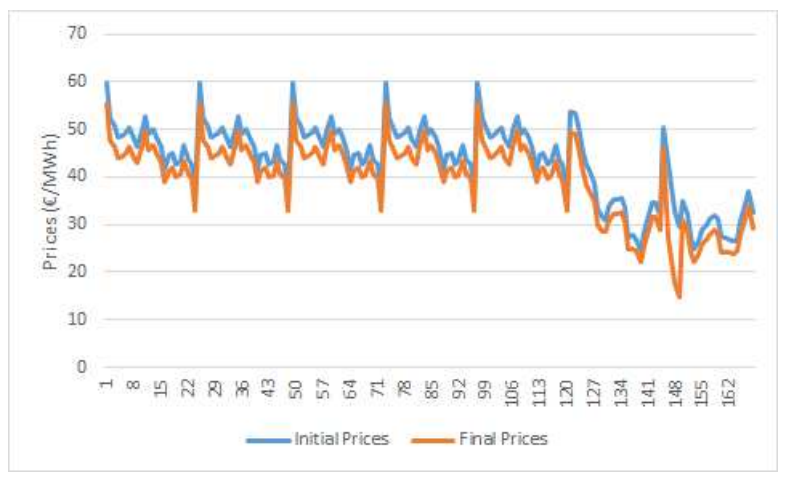

Fig. 5. Case 1 - Initial and final market prices.

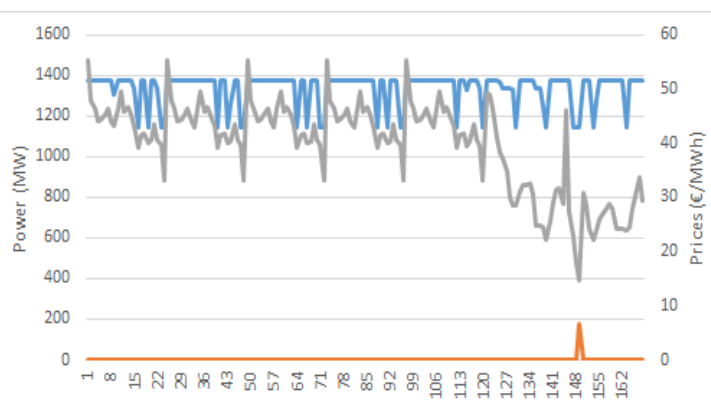

Fig. 6. Case 1 - Final generation and pumping powers and market prices.

\subsection{Case 2-Dry Week}

For the dry week, typical inflows were again provided by EDP Gestão da Produção, SA and the simulation was done setting the initial and final volumes of each station at $20 \%$. Figure 7 presents the prices used in the first run of the HSP problem and the final ones considering the operation decisions of the hydro stations. Figure 8 shows the generation and pumping powers in the 9 stations as well as final prices. In this case, the profit after the first HSP run is $1.220 .419,05 €$ and this value is reduced by $7,0 \%$ to $1.135 .932,77 €$ after 3 iterations.

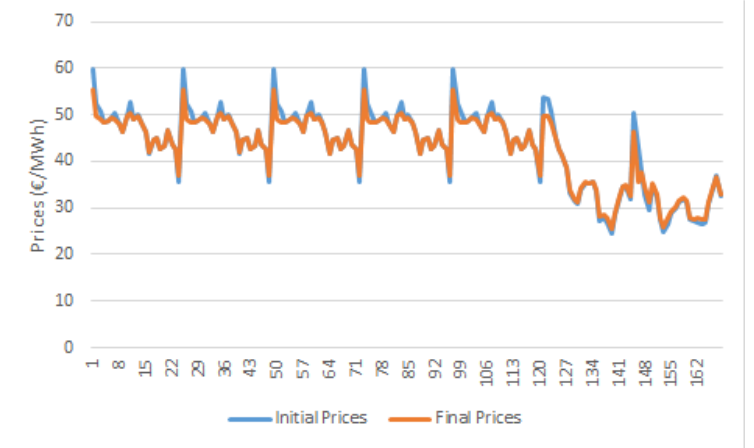

Fig. 7. Case 2 - Initial and final market prices.

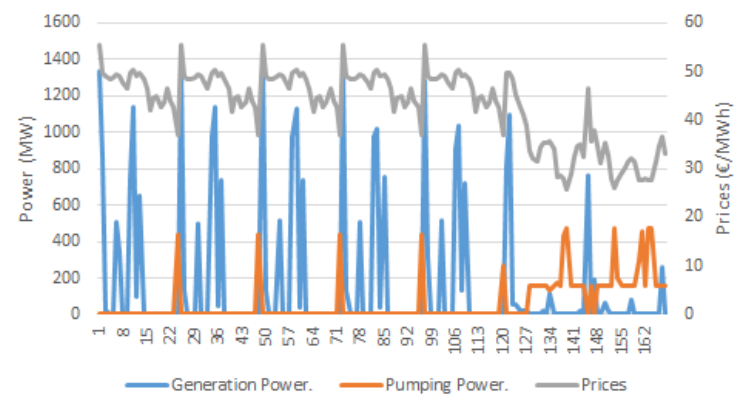

Fig. 8. Case 2 - Final generation and pumping powers and market prices.

These results indicate that the total generation is now much smaller than in Case 1, given the more reduced inflows. On the other hand, pumping is necessary in some periods to enforce the final volume constraint for some stations. As a result of these operation decisions (less generation and more pumping) the final profit is now much more reduced. The initial and final prices are very close all along the week since generation is in general more reduced and pumping, although larger than in Case 1, is still not very intense. In any case, price reductions are visible in Figure 7 when generation is larger and at the end of the week some price increases occur when pumping is larger than generation.

\section{Conclusions}

This paper reports the development of an application to plan the short term operation of a set of hydro stations installed in the same basin and given that some of them are pumping stations. The algorithm includes an iterative process to adjust the market prices taking into account the operation decisions obtained for the stations. It is important to notice that in periods where generation is larger than pumping, the prices tend to decline and if pumping is larger, then the prices tend to increase. As a result the operation profit will get reduced if compared with the one obtained considering that the stations are price takers, that is, after the first run of the HSP problem. As a conclusion, this application can be used by generation agents to model the HSP problem more realistically and to more accurately estimate the profit.

\section{Acknowledgements}

This work was developed in the scope of the MSc Thesis of the first author. The first author wants to thank EDP Gestão da Produção for providing data and also for the useful discussions held during this work.

\section{References}

[1] Sousa, J. C., Mendes, V. T., Saraiva, J. T., "Estimation of the Remuneration of Hydro Plants in a Market Environment Using an Iterative UnderRelaxation Approach", Proceedings of the 2009 IEEE Bucharest Power Tech, Bucharest, Romenia, 28 June 2 July 2009. 
[2] Pousinho, H. M., Mendes, V. M. F., Catalão, J. P., "Profit-Based Head-Dependent Short-Term Hydro Scheduling Considering Risk Constraints", Proceedings 2011 IEEE Trondheim Power Tech, Trondheim, Norway, June 2011, pp 1-6.

[3] Fosso, O. B., Belsnes, M. M., "Short-Term Hydro Scheduling in a Liberalized Power System", Proceedings of the International Conference on Power System Technology, PowerCon 2004, vol. 2, Singapore, November 2004, pp. $1321-1326$.

[4] Chang, S.-C., Chen, C. H., Fong, I. K., Luh, P. B., "Hydroelectric Generation Scheduling With An Effective Differential Dynamic Programming Algorithm", IEEE Transactions on Power Systems, 1990, 5, (3), pp. 737-743.

[5] Martinez, L., Soares, S., "Primal and Dual Stochastic Dynamic Programming in Long Term Hydrothermal Scheduling", Proceedings IEEE/PES Transmission and Distribution Conference: Asia and Pacific, vol. 3, October 2004, pp. 1283-1288.

[6] Shawwash, Z. K., Siu, T. K., Russell, S. O. D., "The B. C. Short Term Hydro Scheduling Optimization Model", IEEE Transactions Power Systems, 2000, 15, (3), pp. 1125 - 1131.

[7] Garcia-Gonzalez, J., Castro, G. A., "Short-Term Hydro Scheduling with Cascaded and Head-Dependent Reservoirs Based on Mixed Integer Linear Programming", Proceedings of 2001 IEEE Porto Power Tech, Porto, Portugal, September 2001.

[8] Naresh, R., Sharma, J., "Hydro System Scheduling Using ANN Approach", IEEE Transactions Power Systems, 2000, 15, (1), pp. 388 - 395.
[9] Wong, K. P., Yong, Y. W., “A Parallel Simulated Annealing Algorithm for Short-Term Hydro Scheduling", Proceedings of the Second International Forum on Applications of Neural Networks to Power Systems, Yokohama, Japan, April 1993, pp. 335-340.

[10] Mantawy, A. H., Soliman, S. A., El-Hawary, M. E., "A New Tabu Search Algorithm for the Long-Term Hydro Scheduling Problem", Proceedings Large Engineering Conference on Power Engineering, LESCOPE'2002, Halifax, Canada, June 2002, pp. 2934.

[11] Sampaio, G. S., Saraiva, J. T., Sousa, J. C., Mendes, V. T., "Optimization of the Operation of Hydro Stations in Market Environment Using Genetic Algorithms", Proceedings of the European Energy Market Conference, EEM'13, Stockholm, Sweden, May 2013.

[12] Leite, P. T., Carneiro, A. F. M., Carvalho, A. L. F., "Energetic Operation Planning Using Genetic Algorithms", IEEE Transactions on Power Systems, 2002, 17, (1), pp. 173 - 179.

[13] Samudi, C., Das, G. P., Ojha, P. C., Sreeni, T. S., Cherian. S., "Hydrothermal Scheduling Using Particle Swarm Optimization", Proceedings of the IEEE 2008 T\&D Conference and Exposition, Chicago, USA, April 2008.

[14] García-González, J., Parrilla, E., Barquín, J., Alonso, J., Sàiz-Chicharro, A., González, A., "Underrelaxed Iterative Procedure for Feasible Short-Term Scheduling of a Hydro Chain", Proceedings of 2003. IEEE Bologna Power Tech, Bologna, Italy, vol. 2, June 2003. 